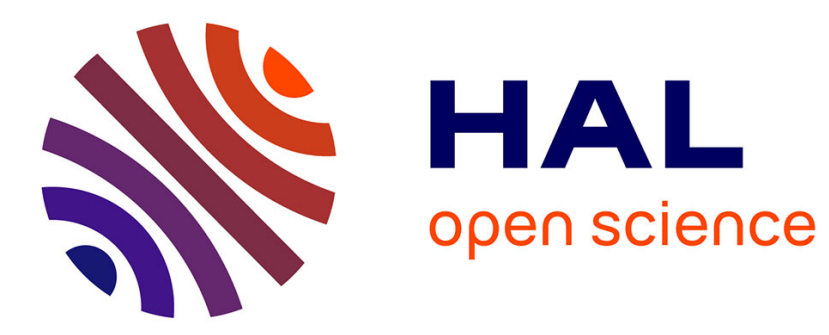

\title{
Wood preservation (carbon sequestration) or wood burning (fossil-fuel substitution), which is better for mitigating climate change?
}

Philippe Leturcq

\section{- To cite this version:}

Philippe Leturcq. Wood preservation (carbon sequestration) or wood burning (fossil-fuel substitution), which is better for mitigating climate change?. Annals of Forest Science, 2014, 71 (2), pp.117-124. 10.1007/s13595-013-0269-9 . hal-01098394

\section{HAL Id: hal-01098394 \\ https://hal.science/hal-01098394}

Submitted on 8 Jan 2015

HAL is a multi-disciplinary open access archive for the deposit and dissemination of scientific research documents, whether they are published or not. The documents may come from teaching and research institutions in France or abroad, or from public or private research centers.
L'archive ouverte pluridisciplinaire HAL, est destinée au dépôt et à la diffusion de documents scientifiques de niveau recherche, publiés ou non, émanant des établissements d'enseignement et de recherche français ou étrangers, des laboratoires publics ou privés. 


\title{
Wood preservation (carbon sequestration) or wood burning (fossil-fuel substitution), which is better for mitigating climate change?
}

\author{
Philippe Leturcq
}

Received: 7 June 2012 / Accepted: 25 January 2013 / Published online: 28 February 2013

(C) INRA and Springer-Verlag France 2013

\begin{abstract}
- Context The effective ways of using wood production with a view to mitigating climate change are still disputed. Currently, there are two major opposing conceptions. One proposes to increase the carbon stock in forests, in wood products or in some kind of long-term wood storage, thus giving primacy to carbon sequestration. The other invokes the concept of biomass carbon neutrality to assert that the substitution of wood for fossil fuels avoids carbon emissions.

- Aim and method This paper contributes to this debate by comparing carbon footprints of heat generation when choosing wood or other fuels as alternatives.

- Result On condition that wood can be preserved with sufficient durability to meet the time frame of the necessary transition towards carbon-free energy resources (decadal to centennial time scales), one can demonstrate that the use of fossil fuels, with the exception of coal, is still preferable. The reasons are that the intrinsic carbon emission factor for wood has the highest value among all fuels in common use and that reference to the concept of wood carbon neutrality neglects the possibility of storing carbon positively in wood for a long time.
\end{abstract}

- Conclusion The conclusion is that to mitigate climate change it is better to store wood than use it as a fuel.

\section{Handling Editor: Shuqing Zhao}

Free-authored paper This research paper is the "full" paper corresponding to a contribution to the International Conference "Tackling climate change" 21-24 May, 2012, Tours (France) [Scientific Parallel Sessions 3-Mitigation 1]

P. Leturcq $(\bowtie)$

Toulouse University (INSA and LAAS-CNRS),

73 allée de Nanbours,

31650 Auzielle, France

e-mail: phleturcq@hotmail.fr
Keywords Carbon footprints · Carbon storage $\cdot$ Wood energy $\cdot$ Mitigation scenarios $\cdot$ Geo-engineering

\section{Introduction}

Using wood to substitute for fossil fuels is generally thought of as contributing to climate change mitigation. Woody resources are regarded as "renewable" and their use as an energy source "neutral" with respect to the greenhouse effect. Accordingly, an increased utilization of wood energy should have no climatic consequence while simultaneously saving fossil energy resources. This view respecting the "carbon neutrality" of wood is questionable (Leturcq 2011) as it presupposes that the carbon mass stored in forests and in wood products remains constant or, in other words, that the fate of wood is oxidation, by combustion or decomposition, at the same rate as it is biologically produced.

This article reappraises the climate impact of wood energy, compared to that of other sources of heat, by taking into account the real properties of the sources, the global warming potential of the emitted carbon dioxide and the possibility of accumulating and preserving wood in the time frame allotted to reduce anthropogenic carbon emissions, which is of the order of half a century (Allen et al. 2009).

\section{Wood burning in the global atmospheric carbon budget}

According to most climate experts, preservation of the biosphere from uncontrolled climate changes requires a drastic short term reduction in carbon dioxide and other greenhouse gases emissions. Halving world carbon emissions before midcentury in comparison with the 1990 value would be a necessary condition for limiting to $2{ }^{\circ} \mathrm{C}$ the global temperature increase relative to the preindustrial level (Meinshausen et 
al. 2009). For developed countries, this implies a cut of carbon emissions of up to $80 \%$ in Europe, and more in Australia and the United States. It is generally considered that the efficient way for that is to reduce fossil fuel consumption. This view is restricted, as the goal is to tackle net emissions, that is to say, the imbalance between carbon emissions and carbon capture. This imbalance is shown in Fig. 1 which indicates the main sources and sinks of atmospheric carbon.

Forests play the dominant role in the land sink. Wood stores carbon that is captured in the atmosphere in the proportion of one ton of carbon dioxide per cubic meter approximately. Burning wood releases this carbon which impacts on the greenhouse effect in the same way as carbon emitted from the other fuels. According to the Food and Agricultural Organisation (FAO 2010), approximately 3.5 billion cubic meters of wood are harvested annually, of which half are used as a source of energy. In addition, emissions arising from the combustion/decomposition of discarded wood products and waste from the wood industry must be taken into account. Therefore, on the rough assumption that the annually harvested wood only replaces the ligneous matter which is oxidized each year (IPCC 1996), the corresponding carbon emissions would amount to 3.5 billion tons of carbon dioxide approximately, that is to say, one gigaton of carbon a year $(1 \mathrm{GtC} / \mathrm{yr})$. This release of carbon is comparable to the figure for land use change, principally deforestation, escaping in the same way from the land carbon sink as illustrated in Fig. 1. So the question arises as to whether or not the use of wood energy (generally, bioenergy) is really beneficial to climate change mitigation.

The advocates of wood energy invariably advance the argument of "biomass carbon neutrality". As long as forests are managed sustainably, they reason, burning wood simply returns to the atmosphere the carbon that was captured by growing trees. Accordingly, setting apart the carbon emissions due to the expense of fossil energy in harvesting, processing, transport and storage operations, the net carbon emission from wood combustion would be zero. A number of energy and environmental policies are erroneously linked to this conception (Searchinger et al. 2009). As an example, the European directive on greenhouse gas emission allowance trading specifies: "the emission factor for biomass should be zero" (European Commission 2003). Such assertion leads to irrelevant calculations of carbon footprints since, as pointed out by a number of authors, the temporal inertia of forest growth, obvious changes in wood stocks and the impact of the land use changes needed for bioenergy productions are disregarded (Johnson 2008; Walker et al. 2010; EEA 2011). Correct carbon accounting rules related to bioenergy, especially wood energy, then becomes a crucial necessity as regards the objective of climate change mitigation (Haberl et al. 2012; Johnson and Tschudi 2012). Of course, a key point is the consideration of the true emission factor of wood relative to the emission factors of other sources of heat (Leturcq 2011).

\section{Wood is a bad fuel as regards carbon emissions}

When comparing the various heat sources: wood, coal, fuel oil, gas or electricity, with a view to climatic impacts, the pertinent characteristic is the emission factor. The emission factor is the amount of carbon (or carbon dioxide) emitted per unit of released energy. Table 1 gives relevant values of this emission factor taken from standard data (IPCC 2006; Concawe/Eucar/JRC 2007) or, for electricity, deduced from the actual "mix" of means of production in Europe (EU-mix) and in France (F-mix) (SoeS 2011). As can be seen, wood as an energy source is a
Fig. 1 Global carbon fluxes (2000-2010 averages). Fluxes are indicated in terms of gigatons of carbon per year (GtC/yr) and could be expressed in units of carbon dioxide as well, using the molecular weight ratio of $44 / 12$. Sources: Global carbon project 2011; FAO 2010

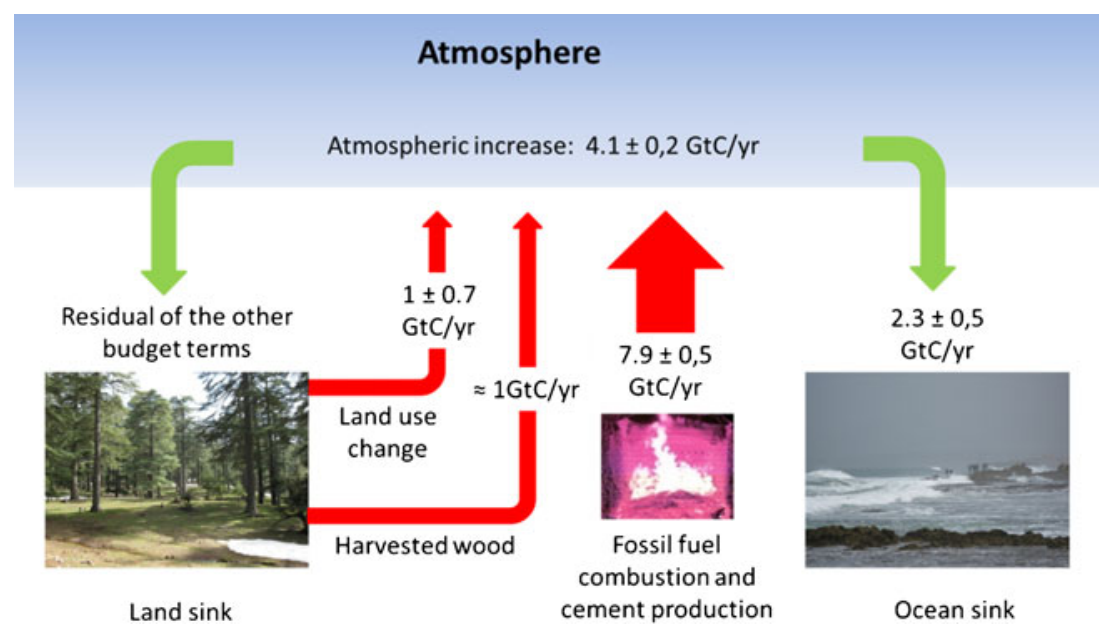


Table 1 The logic of emission factors

\begin{tabular}{|l|c|c|c|}
\multicolumn{1}{|c}{ Resource } & $\begin{array}{c}\text { Emission factor } \\
\text { (tC/toe) }\end{array}$ & $\begin{array}{c}\text { Wood } \\
\text { burning }\end{array}$ & $\begin{array}{c}\text { Wood } \\
\text { preservation }\end{array}$ \\
\hline Wood (anhydrous) & 1.16 & $\mathbf{0}$ & 1.16 \\
\hline Coal & 1.1 & 1.1 & 0.06 \\
Electricity (EU-mix) & 1.06 & 1.06 & 0.1 \\
Fuel oil & 0.84 & 0.84 & 0.32 \\
Natural gas & 0.64 & 0.64 & 0.52 \\
Electricity (F-mix) & 0.25 & 0.25 & 0.91 \\
& & $\begin{array}{c}\text { Avoided emission } \\
\text { (tC/toe) }\end{array}$ & $\begin{array}{c}\text { Net capture } \\
\text { (tC/toe) }\end{array}$ \\
\hline
\end{tabular}

Emission factors are expressed in tons of carbon per ton-oil-equivalent of energy content (tC/toe). The column labeled "Wood burning" indicates the avoided carbon emissions resulting from substitution of wood for other fuels, under the assumption of biomass carbon neutrality. The column "Wood preservation" shows the net carbon capture issued from substitution of fuels or electricity for wood energy, wood being preserved. Sources of emission factor data: IPCC 2006; Concawe/Eucar/ JRC 2007; SoeS 2011

higher carbon emitter than the other listed resources. In spite of this physical evidence, the argument of "biomass carbon neutrality", according to which the emission factor of wood should be set to zero, leads to the conclusion that the replacement by wood energy of other heat sources would avoid carbon emissions, as shown in the third column of Table 1 ("Wood burning"). This point of view is highly questionable. First, "carbon neutrality" is not an intrinsic property of wood, but the result of a special forest management. It presupposes that wood is replaced in growing trees at the same rate as it is harvested. Second, the concept of carbon neutrality disregards the possibility of long-term wood storage, whether in products or otherwise, instead of burning it.

Thus, another argument can be supported. As wood retains 1.16 tons of carbon per ton-oil-equivalent of energy content, its long-term preservation should be counted as a carbon capture. This reasoning leads to the results shown in the right hand column of Table 1. Contrary to the common view, the replacement of wood fuel by other heat sources allows net carbon capture while satisfying the same energy need. Such a substitution would not be very significant in the case of sources with a high emission factor such as coal or electricity generated by fuel-fired plants. The converse would hold if natural gas was used, or electricity if it is produced mainly carbon-free by nuclear, hydraulic and wind plants as is the case in France.

The following example (Fig. 2) gives credit to this view. Let us compare two options $\mathrm{A}$ and $\mathrm{B}$ placing in parallel a forest whose production may be burned or stored, and a gas resource which may also be stored, or used to provide energy. In option A, to meet energy needs, wood is used, gas being kept in its field or in gasholders. In option B, gas is used, the wood being stored. The carbon assessments in both cases are easy to establish, taking into account that the emission factor when burning wood turns into a capture factor of the same value when wood is preserved. If the assumption of "wood carbon neutrality" applies, a flux of 1.16 tons of carbon by ton-oil-equivalent of energy content of the harvested wood should be captured by the forest in the atmosphere. If such an assumption does not hold, the captured flux, represented by $\mathrm{X}$ in Fig. 2, may be larger or smaller than 1.16 tons, but the difference between the carbon budgets of the two options remains independent of $\mathrm{X}$. The balance sheet then indicates that the preservation of wood, which is carbon sequestration, has the advantage over substitution of wood energy for gas. The difference, a net capture, amounts to $80 \%$ of the gas carbon emission. This result applies whatever is the method of forest management, which may be sustainable or not. So, if the concern is to resist climate change, the use of wood for heating instead of fossil fuels and even electricity may be counter-productive.

Comprehensive footprints estimations require additional considerations:

1. Besides the intrinsic emission factors, the emissions related to the exploitation, transportation, processing, packaging and distribution of fuels should be taken into account. The typical values shown in Table 1 would all be modified by such extrinsic data within a broad range of 10 to $20 \%$, but this would not alter the relative rankings.

2. More important is the consideration that carbon sequestration in wood is only temporary. In most cases, even if energetic uses are precluded, wood releases carbon back to the atmosphere as it decomposes more or less slowly under the action of biotic agents. Thus, the comparison between wood energy and other heat sources must include the fate of the harvested wood, if wood is not burnt. Moreover, the carbon mass released into the atmosphere by combustion or decomposition progressively diminishes as it is absorbed by the land and ocean sinks. Thus, carbon assessments that are valid at the moment of heat energy release must be extended up to a time horizon relevant to the goal of climate change mitigation.

\section{Calculation scheme for evaluation of the climate impact}

The Global Warming Potential (GWP) is the recommended metric to compare future climate impacts of emission scenarios (IPCC 2007). The main hypothesis and calculation steps can be summarized as follows: 
Fig. 2 Comparison of carbon assessments of wood and gas burning for the same energy need. Two options are considered: wood burning, gas being kept $(A)$, use of gas, wood being preserved $(B)$. See

Table 1 for emission factor data

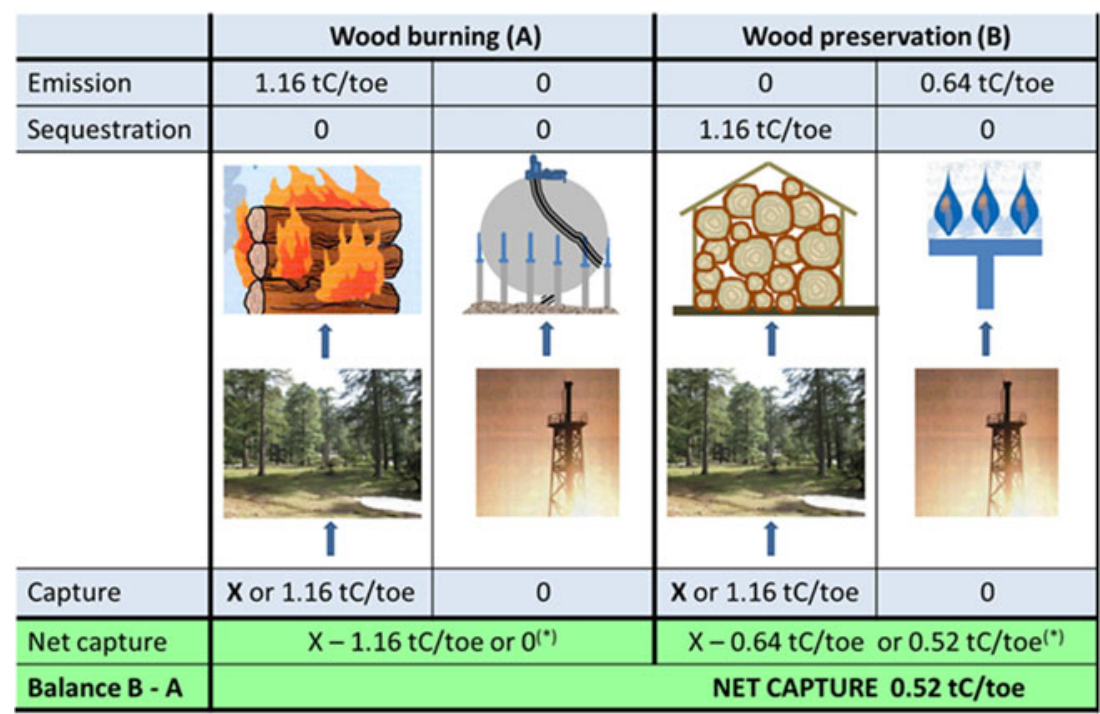

$\left[{ }^{(*)}\right.$ under assumption of biomass carbon neutrality]
1. Figure 3 displays the foreseeable decline of a unit mass of carbon released in the atmosphere at time zero, according to the Bern model of the carbon cycle (Joos et al. 2001). This is considered by climatologists as a pulse response $h(t)$ characterizing the atmospheric system viewed as linear with regard to small perturbations and, to some extent, as time-invariant. This response is not simply exponential since many terrestrial and oceanic mechanisms act to remove carbon with very different time scales, from a few years up to many millenaries. By curve fitting, a representation of the pulse response is obtained in a form appropriate to analysis:

$h(t)=\sum_{i=0}^{3} a_{i} \exp \left(-\frac{t}{\tau_{i}}\right) u(t)$

where $u(t)$ is the unit step function. The parameter values updated in 2007 (IPCC, 2007) are:

\footnotetext{
$a_{0} \approx 0.217 a_{1} \approx 0.259 a_{2} \approx 0.338 a_{3} \approx 0.186$

$\tau_{0} \approx$ millenaries $\tau_{1} \approx 172,9$ years $\tau_{2} \approx 18,51$ years $\tau_{3} \approx 1.186$ years
}

2. According to a basic theorem of linear time-invariant system theory (see for example Keesman 2011), the evolution in the atmosphere of a carbon mass $m(t)$ resulting from a time-dependant emission $e(t)$ can be obtained using the convolution integral:

$m(t)=\int_{0}^{t} e(\tau) h(t-\tau) d \tau$

3. The radiative forcing $R_{\mathrm{F}}(t)$ that represents the change of energy flux entering the atmospheric system as consequence of the intensification of the greenhouse effect, is simply proportional, under assumption of linearity, to the excess carbon mass $m(t)$ :

$R_{F}(t)=\beta m(t)$

where the $\beta$ coefficient value is approximately 6.5 $\times 10^{-15} \mathrm{~W} \cdot \mathrm{m}^{-2} \cdot(\mathrm{kgC})^{-1}$ presently.

4. Finally, the climatic impact is quantified through the GWP, an index which represents the extra energy entering the climate system from the chosen time origin up to a time horizon $\mathrm{TH}$ :

$G W P(T H)=\int_{0}^{T H} R_{F}(t) d t$

\section{Climatic impacts of the heat sources}

Following the example of Fig. 2 for explicative purposes, Fig. 4 prolongs in time the comparison of the carbon

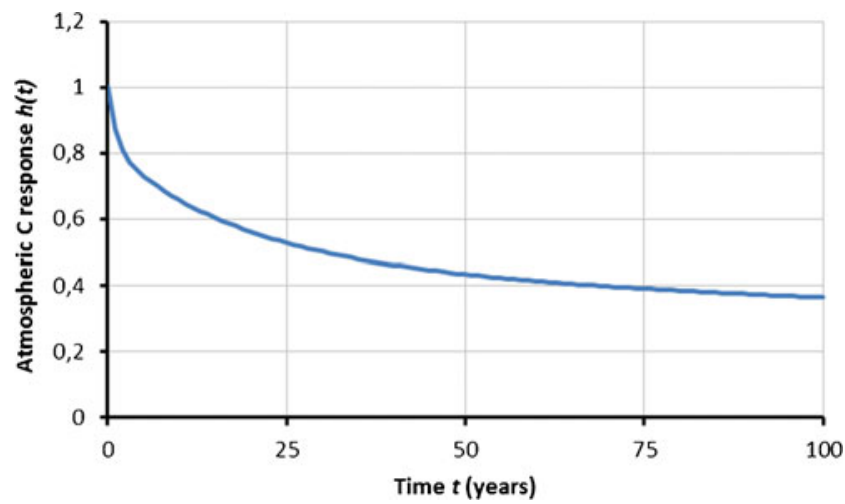

Fig. 3 Decay of a unit mass of carbon (or carbon dioxide) released in the atmosphere at time zero 


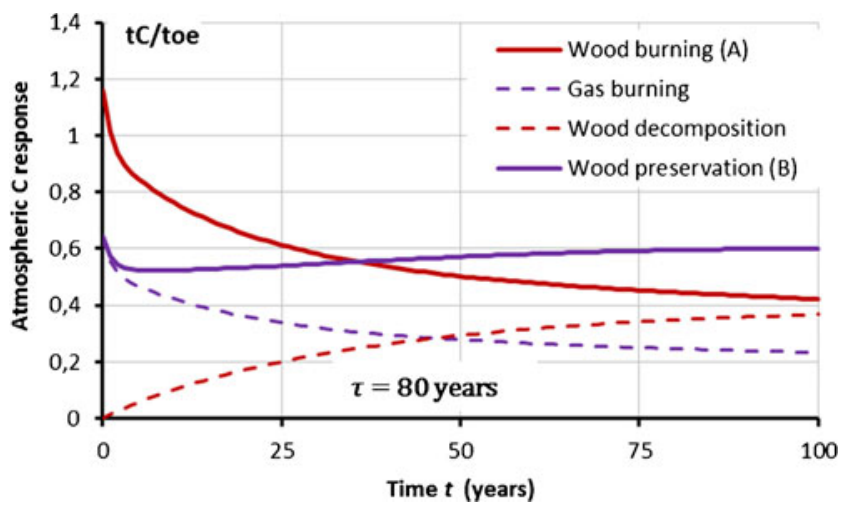

Fig. 4 Evolutions of the carbon mass released in the two options $A$ (wood burning) and $B$ (gas burning, wood being preserved). See example of Fig. 2. The purple curve relating to option $B$ comes from the sum of carbon masses released in the atmosphere by gas burning and wood degradation (dashed curves). The time constant of wood degradation is supposed to be 80 years (half-life of 55 years)

assessments of uses of wood and gas in satisfying the same need of heat energy. In both cases, the carbon mass emitted into the atmosphere by combustion declines progressively. However, in the case of gas utilization, the carbon sequestration in wood cannot be illimitable. A straightforward assumption is that, considering a representative wood stock, the part which returns its carbon to the atmosphere per time unit is more or less proportional to the current amount of wood (Pingoud et al. 2003). That is to say that the wood stock decomposes according to an exponential decay. For purposes of illustration in Fig. 4, the time constant chosen is 80 years, corresponding to a half-life of 55 years. The carbon thus released in the atmosphere adds to the carbon emitted from gas combustion (dashed curves). This leads to the evolution of the overall carbon mass shown by the purple curve in Fig. 4. When comparing this evolution to that resulting from wood burning (red curve), the advantage of substituting gas for wood is evident only for a certain time lapse. This is not surprising since, at a distant time horizon, the total carbon mass remaining in the atmosphere is built up by carbon originating from wood decomposition in addition to that of gas combustion, and therefore is larger than that resulting from single wood burning.

Consequently, the global warming potential of gas utilization, relative to that of wood burning taken as the reference, is reduced for short time horizons but moderately increased for the remote horizons, as shown in Fig. 5. This example suggests that the substitution of gas for wood, not the converse, may reduce significantly the climatic impact of heat production, provided that wood can be preserved for a sufficiently long time. Therefore, the time constant $\tau$ of wood degradation, upon which the time window of a reduced GWP depends, must be considered as another key parameter, besides emission factors relating to the substitute sources.

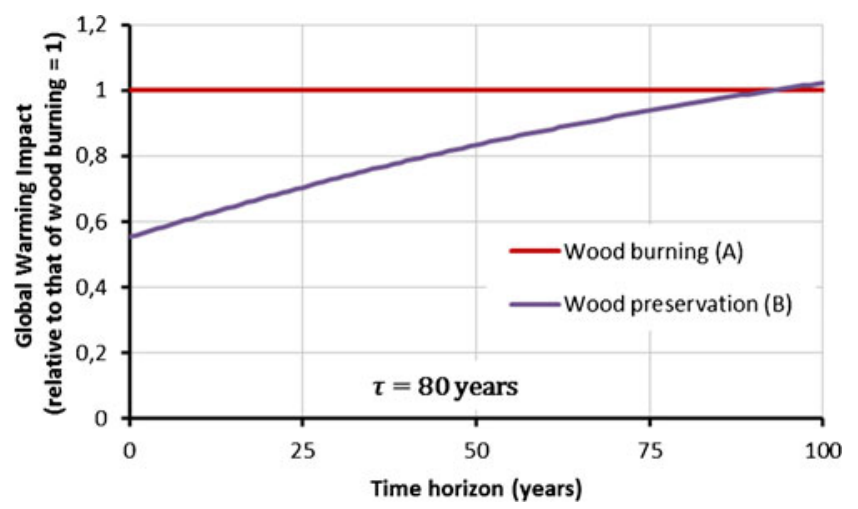

Fig. 5 Global warming potential of option B (gas burning, wood being preserved) relative to that of option A (wood burning) taken as the reference. See example of Fig. 2. The time constant of wood degradation is supposed to be 80 years (half-life of 55 years)

Figure 6 extends the scope of the above example. Two types of heat sources are considered: natural gas (graph a), and electricity produced mainly by carbon-free means as is the case in France (graph b). The time constants of return to atmosphere of the carbon originally sequestered in wood are spread between 20 and 320 years. As might be expected, the replacement of wood energy by other sources of heat is all the more beneficial as the emission factor of these sources is reduced in comparison with that of wood and as wood can be preserved longer. As a rule of thumb, the time window of a reduced global warming potential is in the order of the time constant $\tau$ in the case of gas substituted for wood and three times this time constant in the instance of use of French mix electricity. Of course, in the ideal case of a sufficient disposal of carbon-free energy sources, substitution of these sources for wood energy should lead to an illimitable time window of GWP reduction.

\section{Discussion}

As evidenced by the results shown in Fig. 6, the substitution of wood for fossil fuels does not reduce short term carbon emissions, a conclusion which runs against many currently prevailing assertions. On the contrary, the replacement of wood energy by low-emissive heat sources, including fossil fuels such as gas, or electricity if it is generated from a high proportion of carbon-free primary sources, may offer a carbon capture alternative by way of wood storage, at least for the time allocated to reduce carbon emissions linked to human activities.

The availability of low-emissive substitutes for wood to provide heat, on the one hand, and the feasibility of preserving and storing wood for an extensive period, on the other, both merit further discussion. A third question concerns the long-term climate impact of wood use alternatives, beyond the time horizon of one century that is commonly considered in the evaluation of emission targets. 
Fig. 6 Relative global warming impacts of the substitution of gas (a) or electricity (b French mix) for wood fuel: influences of wood degradation time constant and heat source emission factor. The global warming potential of wood burning is taken as the reference $(=1)$

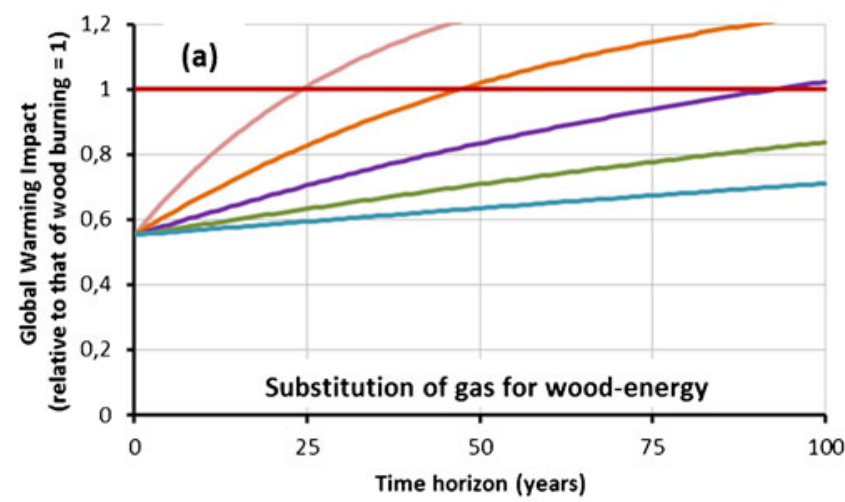

Time constants of wood degradation

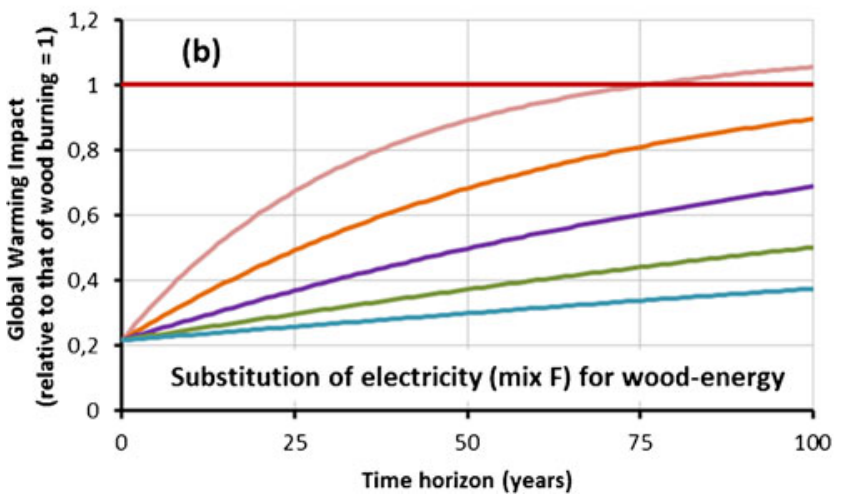

$\tau=20$ years

$\tau=40$ years

$\tau=80$ years

$\tau=160$ years

$\tau=320$ years

wood burning reference
1. Within the present context of climate change, the combustion of any carbonaceous matter, including wood, should be avoided as far as possible. Other sources of energy exist or may be developed, the use of which involves only minor carbon emissions: hydraulic, nuclear, wind, and solar power, for instance. During the transition to decarbonized sources of heat, the consumption of low-emissive fossil fuels, such as natural gas, may be still necessary. Recent estimates of the recoverable gas resources, including shale gas, amount to more than 800 trillion $\mathrm{m}^{3}$ (International Energy Agency 2011), corresponding to a carbon mass of 420 billion tons $(420 \mathrm{GtC})$. The release into the atmosphere of this carbon alone, apart from that of other fossil fuel sources (coal, oil...), would exceed the limits determined for abiding by the $2{ }^{\circ} \mathrm{C}$ temperature rise target. Indeed, according to Meinshausen et al. (2009), the total carbon emissions should be restricted to a level of approximately $270 \mathrm{GtC}$ between 2000 and 2050 (92 GtC have already been emitted between 2000 and 2010) or, according to Allen et al. (2009b) for the long-term, to a level of 1,000 GtC between 1750 and 2500 (500 GtC already emitted to date). These figures show, paradoxically at first glance, that the fear of a lack of fossil fuels is unfounded and should not be invoked to promote the use of wood as a fuel.

2. The conservation of wood extracted from forests may be achieved in two ways
- First, as is most commonly done already, by using wood as a material. This allows not only a direct storage of the carbon drawn from the atmosphere, but also a substitution for other materials whose production requires more energy and generates more greenhouse gas emissions. Increasing the stock of wood products thus contributes positively and doubly to the overall carbon footprint. The average lifetime of wood products is extremely variable, from 6 months to 2 years for paper and cardboard, decades for furniture, from 30 to 100 years and even longer for wood structures in construction (Pingoud et al. 2003). It is important to note that these figures apply in the context of the present day consumer society and that there is no technical obstacle to a significant lengthening of life spans: except for breakage or wear, wood products placed safe from moisture and insect attack are durable. It is also important to stress that it is not so much the working life that matters but the duration of retention of carbon. In the logic of emission avoidance, the recycling of wood products as secondary raw materials must be achieved or, failing that, their managed setting in landfills. The degradation time constants can thus be lengthened considerably. Also, carbon-efficient uses must be found 
for the by-products of thinning, harvest remnants and the wood-waste materials of wood industries. Until now, their use as a source of fuel energy has been an easy way out, all the more so because it is a widely held opinion that they would return anyway, by decomposition, their carbon to the atmosphere. Such a view is not justified. The chemical composition and the physical characteristics of ligneous matter, excepting mechanical properties, are the same as those of timber wood and there is no impediment to various and durable utilizations such as panels, materials for thermal or acoustic insulation, as raw material for chemicals, etc.

- Secondly, useless wood can be stored. Simple storage is one solution, in which case the time constant $\tau$ is that of the natural decomposition of wood under the conditions of storage. Another option is to bury wood: buried wood, after a phase of release of methane which can be recovered in the same way as biogas of farming origin, holds back during centuries and even millenaries a large proportion of the carbon it originally contained (Micales and Skog 1997).

- In any event, in all cases of wood usage other than as an energy source, the values of the time constant $\tau$ could be controlled in an extremely broad interval, as shown in Fig. 6.

3. The fate of emitted carbon beyond the conventional time scope of one hundred year is currently under question. It was long assumed that the residence time of carbon dioxide in the atmosphere would be in the order of one century. This is the value commonly used, within the Kyoto Protocol, as the time horizon for evaluating dangerous anthropogenic impacts on the climate system. However, it is now demonstrated that a noticeable fraction of the emitted carbon (the quasi-equilibrium "airborne fraction") remains in the atmosphere on the time scale of millenaries due to the saturation of the ocean sink. This is taken into account in the evaluations of Section 5 through the IPCC values of the time constant $\tau_{0}$ (millenaries) and the $a_{0}$ coefficient $(0.217$, i.e. a quasi-equilibrium airborne fraction of $22 \%$ approximately). Even if these parameter values are still highly uncertain, the long-term consequences of the anthropogenic carbon emissions are expected to be largely irreversible for thousands of years after emissions stop (Solomon et al. 2009). Consequently, it is imperative not only to reduce as fast as possible the anthropogenic carbon emissions, but also to implement geo-engineering measures that might be able to remove a part of the carbon dioxide already present in the atmosphere. A credible solution is to manage forests with a view to optimum carbon capture, to employ harvested wood as material as long as possible and to bury it, if not suitable for durable uses, as a fossil-like carbon stock (Zeng 2008). In the event, Fig. 1 suggests that $2 \mathrm{Gt}$ of carbon or more could be subtracted from the atmosphere each year, offering a mean to escape dramatic climate changes.

\section{Conclusion}

Three key points need to be emphasized:

1. The concept of "carbon neutrality" in its application to wood is misleading in that it occults the possibility of keeping wood for a long time as a means of carbon storage.

2. Substitution of wood for fossil fuels does not reduce emissions of carbon dioxide because the emission factor of wood has a higher value than that of other fuels in common use.

3. On the contrary, as long as the carbonaceous fuels cannot be replaced by carbon-free energy sources, the replacement of wood energy by low-emissive sources must be favored, in the same way as natural gas is preferred to oil and oil to coal. The foreseeable reduction in the consumption of carbonaceous fuels (energetic transition) will alleviate concerns relating to fossil fuel run out. A prerequisite, however, is to keep long, in one form or another, the substituted wood. Wood conservation is possible over the long term by way of using it as a material and by landfilling or burying.

The efficiency of the terrestrial carbon sink could be substantially increased by significantly expanding forest coverage, increasing the volume of living wood in the forests, using wood as material for durable goods rather than as a fuel, and by wood storage. It is a matter of common sense. So, the present rules of carbon footprint evaluations and the climate policies concerning wood energy, more generally bioenergy, must be deeply revised to remove serious inconsistencies and to alleviate those economic constraints that are hindering a re-orientation of forest management toward high quality timber production and carbon sequestration

Acknowledgments The author is particularly indebted to Henri Dedieu, Brice de Turckheim, Gilles Tierle and Jean-Luc Peyron whose pertinent advices helped some ideas presented herein to mature and to Stuart D. Stein for his editorial assistance. 


\section{References}

Allen M, Frame D, Frieler K, Hare W, Huntingford C, Jones C, Knutti R, Meinshausen M, Meinshausen N, Raper S (2009a) The exit strategy. Nat Reports Clim Chang 3:56-58

Allen MR, Frame DJ, Huntingford C, Jones CD, Jason A, Lowe JA, Meinshausen M, Meinshausen N (2009b) Warming caused by cumulative carbon emissions towards the trillionth tonne. Nature 458:1163-1166

CONCAWE/ EUCAR/ JRC (2007) Well-to-wheels analysis of future automotive fuels and powertrains in the European context; wellto-tank report, version 2c, appendix 1, standard properties of fuels

EEA (2011) Opinion of the EEA Scientific Committee on Greenhouse Gas Accounting in relation to bioenergy. European Environment Agency, 15 September 2011

European Commission (2003) Directive 2003/87/EC of the European Parliament and of the Council of 13 October 2003. Off J Eur Union 275:32-46, 25/10/2003, (Annex IV, p. 44)

FAO (2010) Food and agriculture organisation of the United Nations: global forest resources assessment. FAO For Pap 163:XXI

Global Carbon Project (2011) Global carbon budget 2010 released on 5 December 2011. http://www.globalcarbonproject.org/carbonbudget Data files and a complete description of data sources, calculations and uncertainties for the global carbon budget are available from: http://www.tyndall.ac.uk/global-carbon-budget-2010

Haberl H, Sprinz D, Bonazountas M, Cocco P, Desaubies Y, Henze M, Ole H, Johnson RK, Kastrup U, Laconte P, Lange E, Novak P, Paavola J, Reenberg A, van den Hove S, Vermeire T, Wadhams P, Searchinger T (2012) Correcting a fundamental error in greenhouse gas accounting related to bioenergy. Energ Pol 45C:18-23. doi:10.1016/j.enpol.2012.02.051

IEA (2011) International Energy Agency: are we entering a golden age of gas, World energy outlook 2011 special report (Table 2.1)

IPCC (1996) Revised 1996 IPCC Guidelines for National Greenhouse Gas Inventories: Reference manual, Chapter 5 Land-Use Change $\&$ Forestry (page 5.17, Box 5 «The Fate of Harvested Wood»)

IPCC (2006) Chapter 2: Stationary combustion. In: Eggleston HS, Buendia L, Miwa K, Ngara T, Tanabe K (eds) IPCC Guidelines for National Greenhouse Gas Inventories, Prepared by the National Greenhouse Gas Inventories Programme, vol 2. IGES, Japan

IPCC (2007) Climate change 2007: The Physical Science Basis. Contribution of Working Group I to the Fourth Assessment Report of the Intergovernmental Panel on Climate Change [Solomon S,
Qin D, Manning M, Chen Z, Marquis M, Averyt KB, Tignor M, Miller HL (eds)]. Cambridge University Press. Section 2.10 Global Warming Potentials and Other Metrics for Comparing Different Emissions

Johnson E (2008) Goodbye to carbon neutral: getting biomass footprints right. Environ Impact Assess Rev 29:165-168

Johnson E, Tschudi D (2012) Baseline effects on carbon footprints of biofuels: the case of wood. Environ Impact Assess Rev 37:12-17

Joos F, Prentice C, Sitch S, Meyer R, Hooss G, Plattner G-K, Gerber S, Hasselmann K (2001) Global warming feedbacks on terrestrial carbon uptake under the Intergovernmental Panel on Climate Change (IPCC) emission scenarios. Global Biogeochem Cy 15:891-907

Keesman KJ (2011) System Identification an Introduction, London Springer 2011, ISBN 978-0-85729-521-7

Leturcq P (2011) La neutralité carbone du bois énergie: Un concept trompeur. Rev For Fr (Nancy) LVIII:723-734

Meinshausen M, Meinshausen N, Hare W, Raper SCB, Frieler K, Knutti R, Frame DJ, Allen MR (2009) Greenhouse-gas emission targets for limiting global warming to $2{ }^{\circ} \mathrm{C}$. Nature 458 :11581162

Micales JA, Skog KE (1997) The decomposition of forest products in landfills. Int Biodeterior Biodegrad 39:145-158

Pingoud K, Perälä A-L, Soimakallio S, Pussinen A (2003) Greenhouse gas impacts of harvested wood products; Evaluation and development of methods. VTT Research notes 2189, JulkaisijaUtgivare Publisher (Appendix B)

Searchinger TD, Hamburg SP, Melillo J, Chameides W, Havlik P, Kammen DM, Likens GE GE, Lubowski RN, Obersteiner M, Oppenheimer M, Robertson GP, Schlesinger WH, Tilman GD (2009) Fixing a critical climate accounting error. Science 326:527528

SOeS (2011) Highlights, key figures on climate, France and Worldwide. Commissariat général au développement durable, Service de l'observation et des statistiques, 2011 edition

Solomon S, Plattner G-K, Knuttic R, Friedlingstein P (2009) Irreversible climate change due to carbon dioxide emissions. Proc Natl Acad Sci USA 106:1704-1709

Walker T, Cardellichio P, Colnes A, Gunn J, Kittler B, Persche B, Recchia C, Saah D (2010) Biomass Sustainability and Carbon Policy Study. Manomet Center for Conservation Sciences, June 2010, NCI-2010-03

Zeng N (2008) Carbon sequestration via wood burial. Carbon Bal Manag 3:1. doi:10.1186/1750-0680-3-1 